\title{
Editorial
}

\section{Importance of illustrating art objects(drawing, painting or sculpture) on the front cover}

\author{
Marcelo Moraes Valença1 (D), Juliana Ramos de Andrade ${ }^{1}$ (D), Mario Fernando Prieto Peres ${ }^{2}$ (iD \\ ${ }^{1}$ Federal University of Pernambuco, Recife, Pernambuco, Brazil \\ ${ }^{2} \mathrm{IPq}$ - HCFMUSP, São Paulo, São Paulo, Brazil
}

Marcelo Moraes Valença
mmvalenca@yahoo.com.br
Years ago, we created a section in Headache Medicine entitled NeuroArt ${ }^{1 \cdot 3}$ to value artistic expression that represented the specialty of the study of diverse headache subtypes. As the current trend is to put on the front cover a figure representing the specialty or a theme covered in the issue, we have also used images related to Headache Medicine to illustrate our front covers. The front cover of a book or a scientific journal supports the content and ideas described in the book/period in question.

As a way of praising the work of some artists and their respective work, we have placed some illustrations shown in previous issues of the journal on the home page of the Headache Medicine website (Figure 1).

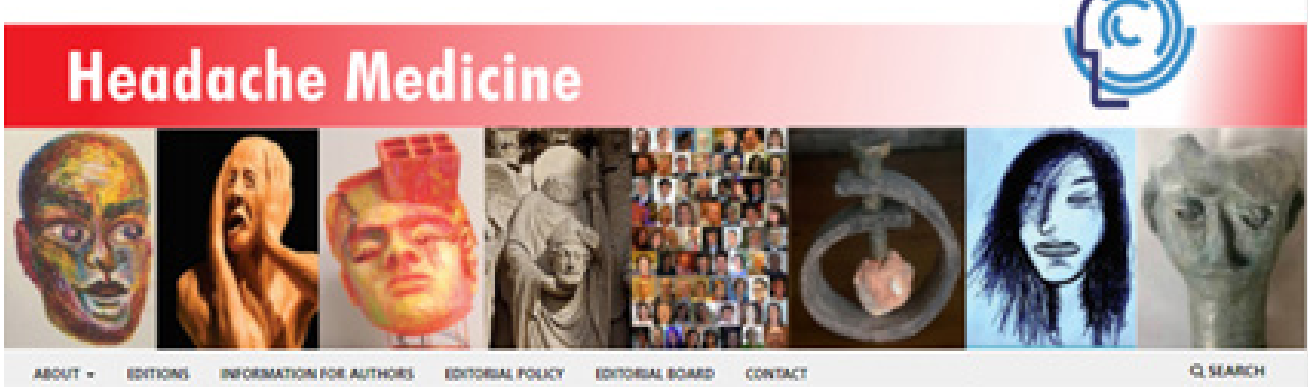

Figure 1. New layout of Headache Medicine website, updated in March, 2021.

Science and art walk together, both seeking a harmonious beauty, establishing some fundamental rules that must be followed, of course with creativity, in a dynamic progression with innovative ways of communicating the new, the revolutionary, making a person think and changing the world in search for greater perfection. 
In the third edition of Headache Medicine 2020, we placed a painting by an anonymous author, whose title is "After a triptan, life is more beautiful," representing nature, with greenery, flowers, and a waterfall. The tendency is to bring illustrations that show the suffering of those who have a headache attack. However, we can also bring images of hope with painting, as in the example, which brings us back to a state of relief, even to know that a given individual is free from that incapacitating migraine crisis that makes one stay in bed, in a dark room, without any noise for several hours of the day.

In the fourth edition of Headache Medicine 2020, we chose a representation of a wooden sculpture also by an unknown author, exquisite, with a high artistic value, showing a doctor being hugged by children with an attitude of suffering, some kneeling, humbly begging almost hopelessly for help. Note that two children are holding their heads with their hands, suggesting they are having headache episodes. The wooden sculpture is part of a graduation photography for the 1949 medical class at the Faculdade de Medicina do Recife. (Figura 2).

In the current edition, the illustration was done by Beatriz Guerra, an 11-year-old girl who took the initiative to ask her classmates at school about the occurrence of headaches. We realized with the three images that the idea of evolution of a migraine attack, with the prodromal period, perhaps with a certain pallor (an autonomic disturbance), followed by a visual aura and later the headache, which is in the frontal region. This is the interpretation of a migraine crisis visualized by this preadolescent girl. It clearly shows that migraine is not just an adult problem and that specialists should guide mothers, fathers, and young children about headaches and available preventive and acute treatment forms. Figure 3 shows some of our published front covers, which have illustrated selected images representing works of art (e.g., drawing, painting, and sculpture).

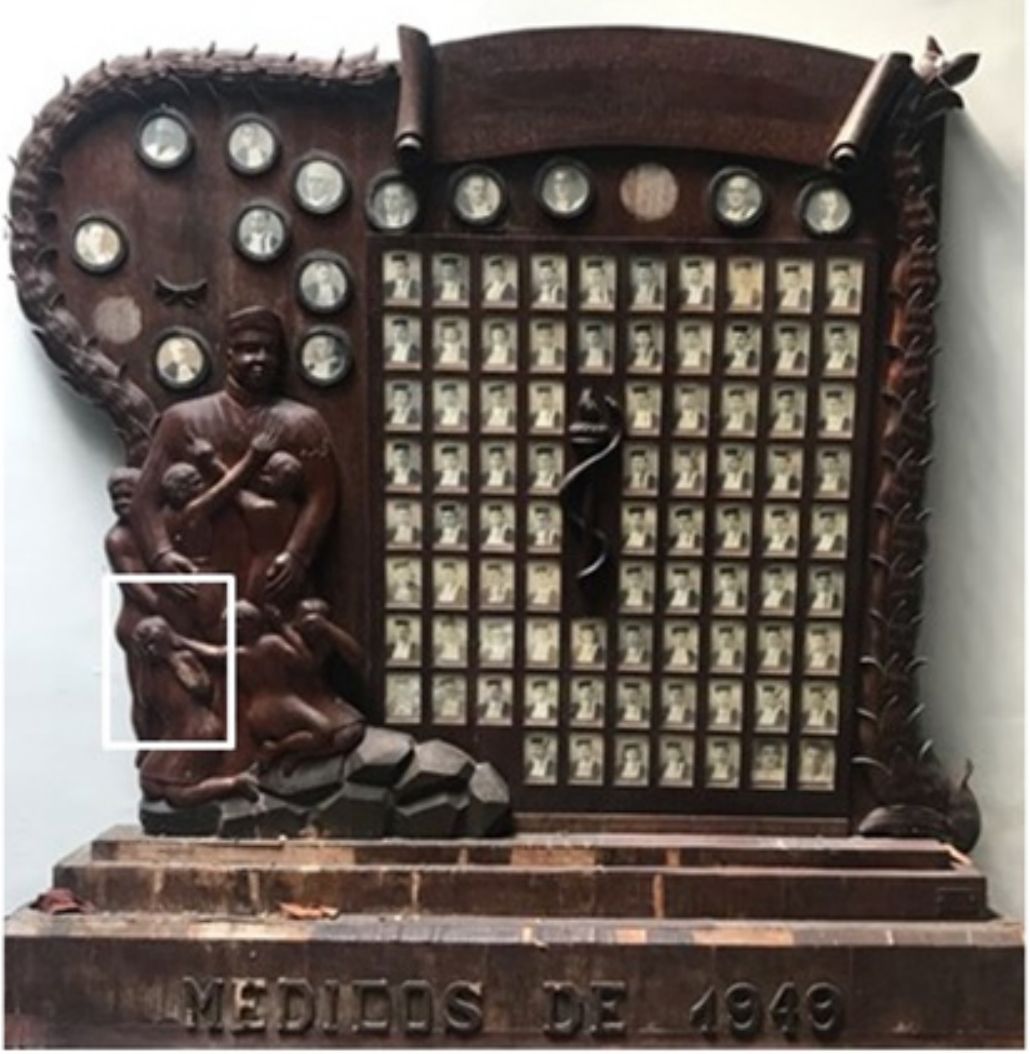

Figure 2. The wooden sculpture is part of a graduation photography for the 1949 medical class at the Faculdade de Medicina do Recife, Brazil. Foto Beleza, Recife, took the photographs. The part of the sculpture used on the front cover is shown with a frame. 

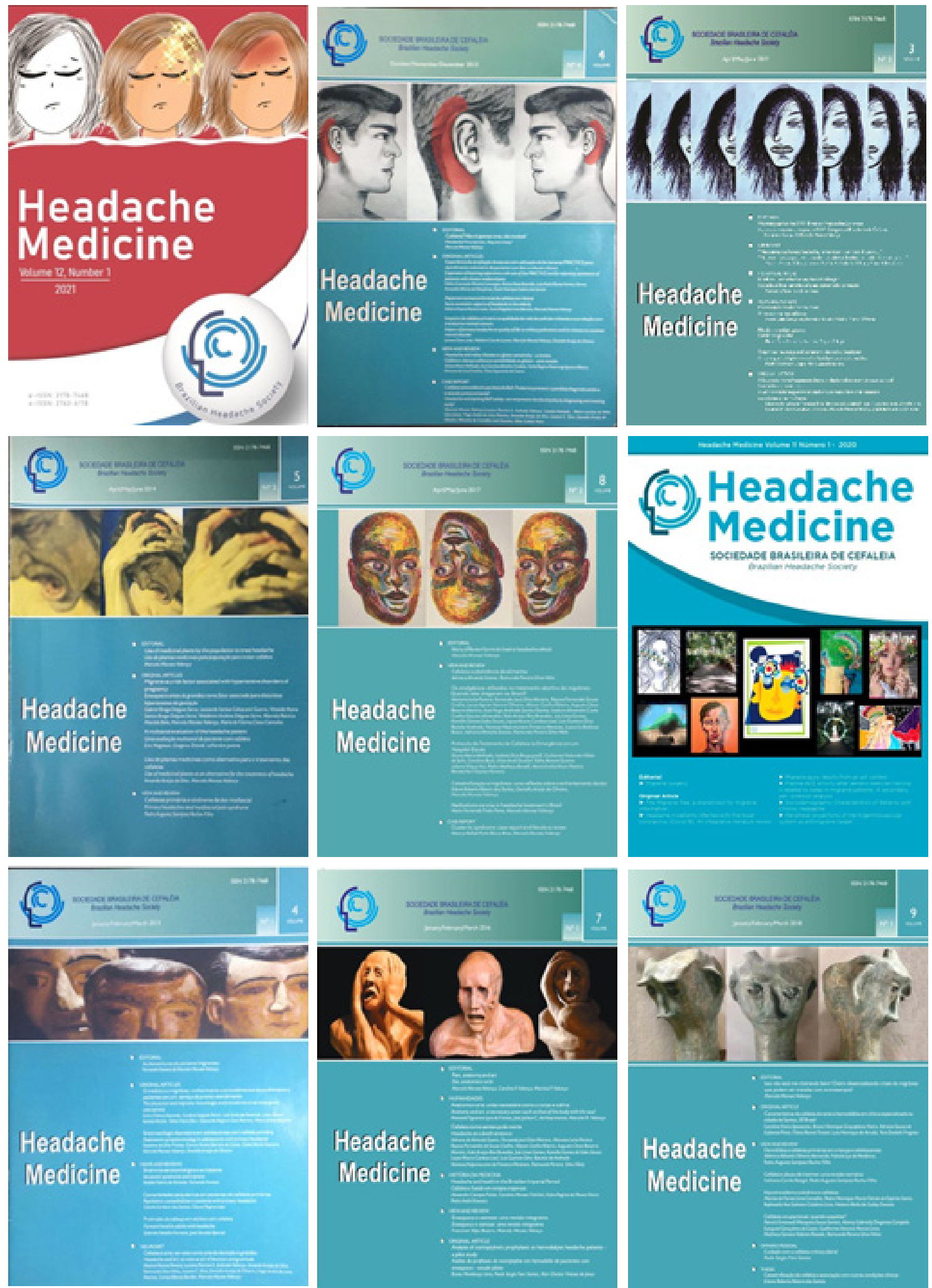

Figure 3. Front covers published in Headache Medicine demonstrating artwork. Superior part: drawings by Beatriz Guerra published in 2021, Larissa Azevedo in 2013, and Sterlin Simons in 2012, respectively. In middle part: paintings by Florentino Bronzino published in 2014, Monica Fidelis in 2018, and digital arts by several artists in 2020, respectively. Inferior part: sculptures by an unknown author published in 2013, Eulâmpio Silva Neto in 2016, and Vera Moraes Valença in 2018, respectively. 


\section{References}

1. Valença MM and Andrade-Valença LPA. Neuroart and headache: the enigmas in the Michelangelo's frescos. Headache Medicine 2011 1;2(4):21 2-215 Doi: 10.48208/HeadacheMed.2011.32

2. Freitas MFL, Nascimento JJC and Valença MM. Anatomy and art: a necessary union such as that of the body with the soul. Headache Medicine 2016;7(1):6-10 Doi: 10.48208/HeadacheMed.2016.2

3. Valença MM and Kowacs F. Migraine-inspired art. Headache Medicine 201 1;2(1):4 Doi: 10.48208/ HeadacheMed.2011.1 